\title{
A linguagem dirigida à criança em uma sala da Educação Infantil bilíngue inglês-português
}

DOI: http://dx.doi.org/10.21165/el.v48i3.2351

\section{Ananda Brasolotto De Santis ${ }^{1}$ Alessandra Del Ré ${ }^{2}$}

\section{Resumo}

Devido a um complexo panorama que envolve questões socioeconômicas e políticolinguísticas, o Brasil apresenta, hoje, uma diversidade de contextos escolares envolvendo o bilinguismo, que carecem de estudos que nos ajudem a melhor compreender os processos de aquisição de linguagem das crianças que os frequentam. Diante disso, esta pesquisa traz uma reflexão sobre a linguagem do educador dirigida à criança (LDC), em uma sala da Educação Infantil de uma escola particular bilíngue portuguêsinglês do estado de São Paulo, e as implicações dessa linguagem para as crianças. Para isso, foram realizadas análises de 11 sessões de vídeos de cerca de 40 minutos, coletados durante um ano nessa escola, focalizando a interação dos educadores e das observadoras-pesquisadoras com três crianças (A., F. e L., entre 2 e 3 anos de idade), em uma sala de aula. Foram observadas características da LDC familiar que se repetem na escola, o que não significa que as crianças adquiram linguagem da mesma forma nesses dois ambientes distintos.

Palavras-chave: bilinguismo; aquisição de linguagem; linguagem dirigida à criança; educação bilíngue.

\footnotetext{
1 Universidade Estadual Paulista (UNESP), Araraquara, São Paulo, Brasil; ananda.santis@unesp.br; https://orcid.org/0000-0002-8015-3482

2 Universidade Estadual Paulista (UNESP), Araraquara, São Paulo, Brasil; del.re@unesp.br; https://orcid.org/0000-0002-6740-9631
} 


\title{
Child-directed Language in a Bilingual English-Portuguese Kindergarten class
}

\begin{abstract}
Due to a complex background involving socioeconomic and politico-linguistic issues existing in Brazil, there is a diversity of scholar contexts involving bilingualism, which lack studies that might lead to a better comprehension of the language acquisition processes by these children. Hence, this research conducts to a reflection over the speech the teacher directs to the child (CDL), in a classroom of a bilingual kindergarten in Portuguese and English in a private school in the state of São Paulo, and the implications of this specific speech for children. For this, eleven sessions in videos of around 40-minutes length have been analyzed. These videos have been collected during one year in this school, focusing on the interaction between teachers and/or observers-researchers and three children (A., F. and L., between 2 and 3 years old) in the classroom. Characteristics of the familiar CDL have been noticed to appear also at school, what, however, does not mean children would acquire language the same way in these two distinct environments.
\end{abstract}

Keywords: bilingualism; language acquisition; child-directed language; bilingual education.

\section{Introdução}

Devido a um panorama complexo de relações políticas e linguísticas, o Brasil apresenta, hoje, uma diversidade de contextos escolares envolvendo questões de bilinguismo, cada qual com suas especificidades: crianças surdas em escolas bilíngues e regulares; escolas de comunidades indígenas; crianças de famílias bolivianas, coreanas, venezuelanas, etc. nascendo e/ou se instalando no Brasil e matriculadas em escolas públicas brasileiras (PIMENTEL; TAMI, 2015); crianças de regiões fronteiriças com o Uruguai, Paraguai e Venezuela que frequentam escolas brasileiras (HERNAIZ, 2007); crianças estrangeiras e/ou brasileiras, filhas de pais estrangeiros morando no Brasil, que frequentam escolas internacionais (americana, francesa etc.); e crianças brasileiras, filhas de pais brasileiros que querem proporcionar a seus filhos uma educação que envolva diversas culturas e possa torná-los cidadãos globais.

Essa última situação, relativamente recente no Brasil, tem criado um outro tipo de demanda de escola bilíngue (MATTOS, 2013, PERRI, 2013), que vem crescendo no país graças à globalização e à necessidade de uma formação escolar que envolva o conhecimento e o rompimento de fronteiras, incluindo, além do português (PB), a instrução em uma outra língua (L2) com alto prestígio social, frequentemente o inglês, que possa ampliar as oportunidades dos indivíduos em formação nessas escolas em um mundo multicultural. 
Essa demanda tem explicação, segundo Marcelino (2009), no ensino de língua estrangeira pouco efetivo em escolas regulares no Brasil, que fez com que, em um primeiro momento, as escolas de idiomas fossem muito procuradas como formação complementar; em seguida, algumas escolas regulares privadas passassem a terceirizar o ensino de línguas para escolas de idiomas, e assim criou-se um contexto que proporcionou a criação de escolas bilíngues, com grande aceitação por parte dos pais. Além dessa questão que possibilitou a aceitação e popularização dessas escolas, o autor menciona um dos fatores que mais leva os pais a confiarem nas possibilidades que essas escolas proporcionam aos seus filhos: "A escola bilíngue deveria ser a nova concepção de escola, a partir de um mundo mais globalizado, o lugar onde a troca de conhecimento e rompimento de fronteiras ocorre. Isso, por si só, justifica a necessidade de uma outra língua como veículo de instrução." (MARCELINO, 2009, p. 11).

Esse modelo de escola bilíngue é, algumas vezes, diferenciado de outros contextos de bilinguismo na educação no Brasil, como mencionamos anteriormente, por termos como escola bilíngue de prestígio ou de escolha (CAVALCANTI, 1999, MEGALE, 2005), porém são termos não muito habituais. Comumente, essas escolas têm sido chamadas no estado de São Paulo simplesmente de escolas bilíngues, e é com os dados de uma escola bilíngue como essa que o presente trabalho foi desenvolvido.

A fim de analisar esses dados, partimos de uma perspectiva dialógico-discursiva sobre a Aquisição da Linguagem baseada no Círculo de Bakhtin (BAKHTIN; VOLOCHINOV, 1988, BAKHTIN, 1997; DEL RÉ; DE PAULA; MENDONÇA, 2014 a e b), entendendo que a constituição da criança como sujeito se dá através da interação com o outro, por meio da linguagem que ela adquire, ao mesmo tempo em que a criança contribui para a constituição dos sujeitos com quem interage.

Nesta pesquisa, focalizamos a interação entre professores da escola, em situação de aula, e três crianças pequenas (A., F. e L.) entre 2 e 3 anos de idade, buscando pontuar características da linguagem dirigida à criança (LDC) pelo educador em situação escolar, e identificar pontos comuns e divergentes que dizem respeito à linguagem familiar dirigida à criança descrita na literatura e, assim, trazer reflexões sobre esse registro de fala particular no contexto escolar bilíngue.

A linguagem com que a criança tem contato é, mesmo dentro do útero, e desde o primeiro contato da criança com a mãe após o nascimento, carregada de emoção e afetividade. A língua da mãe, carregada dessa afetividade, revela-se fundamental no processo de aquisição da linguagem e da constituição da criança enquanto sujeito, que se constitui na e pela linguagem. A criança, em seu processo de constituição, está também adquirindo a(s) sua(s) primeira(s) língua(s) e experimentando as primeiras impressões e sensações do mundo por meio dela(s). Por isso, estudar esse processo tão encantador da entrada da criança na língua(gem) é fundamental e apresenta contribuições grandiosas não 
apenas para a área de Aquisição da Linguagem, mas também para o campo educacional, que necessita de uma - ou mais - língua(s) como veículo de ensino e transmissão de conhecimento no processo de formação da criança.

Isso se torna ainda mais relevante em um contexto atual, no qual as crianças, cada vez mais cedo, por diversas razões, estão em contato com mais de uma língua nos meios em que vivem, e têm motivações para formarem-se indivíduos multiculturais.

\section{Fundamentação teórica}

Adotamos para este projeto uma perspectiva dialógico-discursiva de aquisição de linguagem (DEL RÉ; DE PAULA; MENDONÇA, 2014 a e b) ancorada em conceitos trazidos pelo Círculo de Bakhtin $(1988,1997)$, posto que acreditamos que o sujeito se constitui na e pela linguagem, e a criança, igualmente, adquire linguagem pela interação com o outro, com outros discursos. Ao mesmo tempo, a criança, quando se coloca na interação com o outro, mesmo antes de dizer as primeiras palavras, também reconstrói o discurso do outro. Assim sendo, a criança começa a constituir-se através da linguagem que, primeiramente, a mãe, e então outras pessoas próximas à criança dirigem a ela, desde muito cedo.

Enxergamos, assim, uma forte conexão entre as discussões do Círculo de Bakhtin sobre a relação entre sujeitos, seus discursos e a constituição do sujeito na relação com o outro por meio da linguagem se pensarmos na LDC e na sua relação com a produção da criança, como demonstraremos mais adiante com exemplos de encadeamento de enunciados retirados de trechos dos vídeos coletados na escola bilíngue. O que a criança faz não é simplesmente repetir tudo o que o adulto diz, ela produz enunciados e reconstrói sentidos em outros contextos. A criança também não aceita todas as propostas que o adulto dá quando, por exemplo, ele tenta reformular o que a criança diz. A criança também se coloca no discurso, expressando sua singularidade (DEL RÉ; HILÁRIO; VIEIRA, 2012), podendo mudar o caminho da conversa proposta pelo adulto e, assim, constituir esse adulto, que não para de se ressignificar por meio da linguagem e da relação com o outro.

Com efeito, assim que o homem começa a viver-se por dentro, encontra na mesma hora os atos - os de seus próximos, os de sua mãe- que se dirigem a ele: tudo quanto a determina em primeiro lugar, a ela e a seu corpo, a criança o recebe da boca da mãe e dos próximos. É nos lábios e no tom amoroso deles que a criança ouve e começa a reconhecer seu nome, ouve denominar seu corpo, suas emoções e seus estados internos; as primeiras palavras, as mais autorizadas, que falam dela, as primeiras a determinarem sua pessoa, e que vão ao encontro da sua própria consciência interna, ainda confusa, dando-lhe forma e nome, aquelas que the servem para tomar consciência de si pela primeira vez e para sentir-se enquanto coisa-aqui, são as palavras de um ser que a ama. (BAKHTIN, 1997, p. 67-68). 
Entendemos que a língua é carregada de emoções, significações e ideologias que se (re) constroem na criança em suas interações, por meio do que elas ouvem e dos discursos que elas produzem, reconstruindo-os com novos sentidos durante a comunicação verbal viva que se efetua com os indivíduos que as rodeiam.

\begin{abstract}
A criança começa a ver-se, pela primeira vez, pelos olhos da mãe, é no seu tom que ela começa também a falar de si mesma, como que se acariciando na primeira palavra pela qual expressa a si mesma; assim ela emprega, para falar da sua vida, das suas sensações internas, os hipocorísticos que lhe vêm da mãe: tem sua "babá", faz sua "naninha", tem "dodói", etc., e, dessa maneira, determina a si mesma e a seu próprio estado através da mãe, através do amor que ela lhe traz na qualidade de destinatária de seus favores, de suas carícias, de seus beijos. Sua forma parece trazer a marca do abraço materno. (BAKHTIN, 1997, p. 68).
\end{abstract}

A LDC foi alvo de muitos estudos na década de 70, referida como manhês, termo muito mais ligado à fala da mãe dirigida à criança e por esta razão não será adotado neste artigo. Foi uma época de muitos estudos sobre o tema, depois que Chomsky (1965) usou essa fala como argumento a favor da sua teoria da Gramática Universal, segundo a qual, se à criança é dirigida uma fala "inadequada", como ela seria capaz de se corrigir e desenvolver uma gramática "adequada" da fala? Depois disso, surgiram algumas ideias de que essa linguagem seria negativa para a criança, e muitos estudos seguintes criticando essa proposta por não trazer os efeitos dessa linguagem nas crianças, como consideram Snow e Ferguson (1977) em um levantamento de vários estudos sobre a LDC.

A LDC se apresenta, pelo menos em grande parte da cultura ocidental, como um registro de fala particular, modalizado por qualquer indivíduo que já tenha adquirido a linguagem (inclusive crianças mais velhas) e, mesmo sem se dar conta, ajustam sua linguagem à do interlocutor. Essa ação de ajustar a linguagem à da criança, popularmente designada por "falar com voz de bebê", ao contrário do que se poderia imaginar, parece favorecer o desenvolvimento da linguagem pela criança, na medida em que permite dar continuidade à conversação entre os parceiros conversacionais (AIMARD, 1998; FONSECA; SALOMÃO, 2005).

Tal linguagem particular é conteúdo de diversos estudos em aquisição da linguagem em contexto familiar, e tem características que marcam diferenças entre a LDC e a linguagem dirigida ao adulto, como simplificação, clareza, brevidade, modificações na frequência fundamental, uso de falsete, grande número de perguntas e imperativos, itens lexicais infantilizados, como: "dodói", "papá", repetição silábica, diminutivos e onomatopeias (CAVALCANTE, 2003).

Para analisar essa LDC a partir dos dados de vídeo, trabalharemos com uma análise multimodal (CAVALCANTE, 2018; MCNEILL, 1985; KENDON, 1982), pois consideramos os 
gestos, os olhares e a prosódia - esta última de forma ainda não sistemática neste artigo - na nossa análise como elementos de estatuto linguístico, que atribuem significado e conferem sentido ao discurso, sejam eles acompanhados ou não da fala pelo registro oral.

É sob essas perspectivas relativas à aquisição da linguagem e seu processo vinculado à LDC que lançaremos o olhar para a linguagem que o adulto-professor dirige à criança em situação escolar e sua relação com o processo de aquisição/aprendizagem das crianças em uma escola bilíngue de imersão (BAKER, 2001).

De acordo com as considerações de Baker (2001), a educação bilíngue de imersão é o modelo de educação bilíngue de maior força e reconhecimento, justamente por ser destinada à aprendizagem de uma língua pretendida e de prestígio na sociedade. Esse modelo escolar surgiu no Canadá em 1965, quando alguns pais anglófonos de classe média convenceram a administração da escola a criar uma classe experimental de educação infantil (El) em francês.

Os objetivos dessa escola foram determinados para que os estudantes: (1) tornem-se competentes para falar, ler e escrever em francês; (2) atinjam os níveis normais do currículo, incluindo de língua inglesa; (3) apreciem as tradições e a cultura tanto do Canadá francófono quanto anglófono. Em resumo, os objetivos eram tornar as crianças bilíngues e biculturais sem perda de conquistas [em nenhuma das línguas/culturas em que estavam inseridas]. Tipicamente a educação bilíngue tem mais do que objetivos de "educação efetiva", consciente ou inconscientemente, vantagens econômicas e empregatícias também podem estar presentes. (BAKER, 2001, p. 204-205, tradução nossa³).

Essa definição está vinculada ao que Cavalcanti (1999) chama de bilinguismo de elite ou bilinguismo de escolha, relacionado ao ensino, no Brasil, de línguas prestigiadas nacional e internacionalmente, ligado ou não ao ensino de português.

Acrescentamos ainda que um fator determinante a essa classificação é a ausência de motivação imediata para tal contexto escolar bilíngue. Essas situações diferem dos contextos bilíngues de minorias linguísticas - como as escolas que recebem imigrantes,

3 No original: "The stated aims were for students (1) to become competent to speak, read and write in French; (2) to reach normal achievement levels throughout the curriculum including the English language; (3) to appreciate the traditions and culture of French speaking Canadians as well as English speaking Canadians. In short, the aims were for children to become bilingual and bicultural without loss of achievement. Typically bilingual education has more than 'effective education' aims, so subconsciously or consciously economic and employment advantages may also have been present (see later)". 
filhos de pais que têm uma língua materna diferente do PB, surdos e indígenas. Os alunos que frequentam esse modelo de escola bilíngue no Brasil frequentemente têm o PB como língua materna, inserem-se em uma comunidade familiar falante de PB e, por habitarem um país em que essa é a língua oficial, a utilizam majoritariamente em suas interações cotidianas. Mesmo sendo expostos desde muito cedo à outra língua na escola - algumas crianças entram nessa escola por volta dos seis meses de idade, muitas vezes a necessidade de comunicação na outra língua não é imediata.

Consideramos ainda, vinculando essas definições com as considerações de Megale (2005) e Marcelino (2009) sobre educação bilíngue no Brasil, que uma escola bilíngue de escolha ou de prestígio não é necessariamente uma escola bilíngue de imersão; ela pode ser também uma escola internacional, com o currículo voltado para a formação idêntica à formação no exterior, e com fins de possibilitar ao aluno a obtenção de diploma reconhecido no exterior. As escolas bilíngues de imersão, de acordo com Baker (2001), estão mais relacionadas a objetivos de domínio de mais de uma língua e cultura.

Embora em um contexto linguístico diferente daquele da criação das escolas bilíngues de imersão no Canadá, o modelo foi adaptado para o Brasil e costuma seguir os mesmos padrões do canadense aqui mencionado, com currículo cumprido nas duas línguas. Apesar disso, não há, ainda, uma legislação que defina ou classifique esse modelo de escolas bilíngues no Brasil.

Quanto ao conceito de bilinguismo que trataremos neste projeto, ressaltamos que não há um consenso na definição do termo, embora haja muitas tentativas de definição (DE HOUWER, 1990, HARMERS; BLANC, 2000, BIJELJAC-BABIC, 2017, entre outros), portanto, adotaremos aquela que mais vai ao encontro da nossa perspectiva teórica, a saber, a que considera em que condições socioculturais se dão as interações bilíngues e que tipos de interação incentivam a produção do bilinguismo (GROSJEAN, 1982).

Tendo em vista essas discussões e a oscilação, igualmente, na definição desse modelo de escola bilíngue, preferimos usar, como dissemos, apenas o termo escola bilíngue de imersão ou simplesmente escola bilíngue, como essas escolas são conhecidas no estado de São Paulo, a fim de não Ihes imputar, talvez, uma conotação negativa.

\section{Metodologia}

Os dados utilizados para esta pesquisa foram registrados em vídeo em uma sala de aula de Ensino Infantil bilíngue. Três dessas crianças foram focalizadas durante as filmagens: A. $(2 ; 6$ - 3;5), F. $(2 ; 5$ - 3;3) e L. $(2 ; 9$ - 3;7), junto com uma professora e com a presença de duas observadoras responsáveis pelas filmagens. 
Com autorização dos responsáveis pelas crianças, da coordenação da escola, das professoras e com aprovação do comitê de ética de pesquisa (CAAE: 55829816.0.0000.5400), os registros foram realizados uma ou duas vezes por mês, alternando uma vez na sala de aula com todas as crianças de uma turma, inclusive A., F. e L., outra em uma sala separada apenas com as três crianças - que eram retiradas da turma para essas filmagens -, uma professora e duas observadoras. A professora e as observadoras não eram sempre as mesmas a cada registro. As professoras e observadoras são brasileiras, falantes de PB como língua materna e de inglês como L2.

A coleta de dados foi feita com duas câmeras a cada sessão, por isso a presença de duas observadoras. Uma delas ficava diante de uma câmera fixa em um tripé, em uma posição que proporcionasse uma visão geral da sala; e a outra ficava com uma segunda câmera, em movimento. A cada gravação os papéis se invertiam e quando faltava uma observadora, ou uma delas estava em interação com as crianças e precisava das mãos livres, a câmera apoiada no tripé era pouco movimentada.

Todas as crianças são filhas de pais não-falantes de inglês como língua materna, nasceram e moram no Brasil e frequentam essa escola bilíngue desde 8 meses/1 ano de idade. Trata-se, portanto, de um estudo de natureza qualitativa e longitudinal, com análise dos dados coletados durante um ano.

Vale ressaltar o papel das observadoras enquanto sujeitos na interação, ainda que elas tenham interagido pouco com as crianças e professoras. Deve-se observar, igualmente, que o fato de saberem que estavam sendo filmadas pode ter interferido de alguma forma na interação entre a professora e as crianças. Muito embora se saiba que, em geral, os participantes logo se esqueçam que estão diante de uma câmera, não se pode descartar totalmente uma possível interferência nos resultados.

Realizamos, no primeiro semestre de coletas, de agosto a dezembro de 2016, uma filmagem a cada duas semanas, com duração entre 30 e 60 minutos, referentes ao tempo de uma ou duas atividades propostas para as aulas, procurando filmar atividades diferentes a cada sessão. No segundo semestre de filmagens, de março a junho de 2017, o espaço de tempo entre as filmagens foi maior e a duração de cada sessão, a mesma.

Nesse período, foi realizada em média uma filmagem por mês, alternando entre a turma cheia e as três crianças em sala separada, totalizando 11 sessões de vídeo. A tabela abaixo mostra os detalhes das sessões de 1 a 11. As informações das linhas correspondem ao número da sessão; à data de filmagem; às crianças presentes - se apenas A., F. e L. separados da turma ou a turma toda -; às iniciais das professoras presentes na interação - na sessão 2, houve um momento em que as observadoras ficaram sozinhas com as crianças e, por essa razão, uma das observadoras interagiu mais com elas -; e ao(s) idioma(s) predominantemente proposto(s) pelas professoras naquela interação. 
Tabela 1. Detalhes das sessões de filmagem na escola

\begin{tabular}{|c|c|c|c|c|c|c|}
\hline Sessão & 1 & 2 & \multicolumn{2}{|l|}{3} & 4 & 5 \\
\hline Data & 19/08/16 & 06/09/16 & \multicolumn{2}{|c|}{ 22/09/16 } & $21 / 10 / 16$ & $01 / 11 / 16$ \\
\hline Crianças & Turma & A. F. L. & \multicolumn{2}{|l|}{ Turma } & A. F. L. & Turma \\
\hline Idioma & $\begin{array}{l}\text { Inglês, depois } \\
\text { português }\end{array}$ & Inglês & Inglês & \multicolumn{2}{|c|}{ Português } & Inglês \\
\hline Sessão & 6 & 7 & 8 & 9 & 10 & 11 \\
\hline Data & 18/11/16 & $07 / 12 / 16$ & 20/04/17 & 16/05/17 & 06/06/17 & $27 / 06 / 17$ \\
\hline Crianças & Turma & A. F. L. & Turma & A. F. L. & Turma & A. F. L. \\
\hline Idioma & Inglês & Inglês & Inglês & Inglês & Português & Português \\
\hline
\end{tabular}

Fonte: Elaboração própria

Em seguida, os vídeos foram assistidos e parcialmente transcritos, em função dos objetivos deste trabalho, a partir das normas CHAT, do programa CLAN, fornecido gratuitamente pela base de dados CHILDES (MACWHINNEY, 2000) e traduzidas para o português (DEL RÉ; HILÁRIO; VIEIRA, 2012, DEL RÉ; HILÁRIO; MOGNO, 2012).

Fizemos uma seleção de aspectos da LDC descritos na literatura sobre LDC em contexto familiar e relacionados ao bilinguismo e focalizamos alguns desses aspectos para analisar os dados da LDC do educador, nesse contexto escolar bilíngue. Elencar algumas características e constituir uma tabela com esses dados nos auxiliou no momento da análise, em que pudemos observar características semelhantes e distintas da LDC nesse contexto escolar em relação àquela descrita na literatura como LDC familiar. A partir desse levantamento, pretendemos contribuir para a constituição de um campo de pesquisas em aquisição de linguagem sobre a LDC na escola.

Além da observação dessa LDC, as filmagens nos deram uma amostra do processo de aquisição da linguagem dessas crianças e sobre o modo como elas estão lidando com o inglês que é falado pela professora durante as aulas.

\section{Resultados}

\section{Características da LDC familiar nos dados escolares}

Conforme apontado anteriormente, a literatura em LDC em contexto familiar traz como principais características desse registro: simplificação, clareza, brevidade, modificações na frequência fundamental, uso de falsete, grande número de perguntas e imperativos, 
itens lexicais infantilizados, repetição silábica, diminutivos e onomatopeias (CAVALCANTE, 2003). Ainda é comum que o adulto reformule ou faça uma dedução do que ele assume que a criança queira dizer.

Selecionamos, para este artigo, algumas das características trazidas pela literatura sobre LDC em contexto familiar para serem analisadas nos registros de fala dos professores da escola, a fim de desvendar se os professores da El dessa escola empregam uma linguagem especial ao se dirigirem às crianças no contexto escolar, e como isso ocorre nas duas línguas da escola: português e inglês.

Para isso, selecionamos algumas dessas características, que buscamos nos dados:

a) Léxico infantilizado: se há repetição de sílabas iguais na expressão de uma palavra, como a repetição da primeira sílaba do nome da criança para referir-se a ela, diminuição ou simplificação de palavras específicas, onomatopeias, etc. O que a literatura chama de léxico infantilizado é como dizer "miau" para o gato, "pepeta" para chupeta, "papá" para comida, etc.

b) Dedução ou reformulação do enunciado da criança: É comum que o adulto, em seu esforço para compreender a criança, reformule e/ou deduza o conteúdo de seus enunciados e acrescente nova informação.

Incluímos dois aspectos da LDC relacionados à direção da fala à criança bilíngue:

c) Introdução da língua: se o interlocutor sinaliza à criança de alguma forma que naquele momento vão falar ou que estão falando em uma determinada língua.

d) Demanda para falar em uma determinada língua: se o interlocutor demanda à criança que ela fale em uma língua ou em outra.

Outro aspecto levantado é o da diferença prosódica, que não será aqui explorado. Uma primeira observação, comparando com a forma como se dirige a um adulto, nos mostra que a entonação na fala da professora muda quando ela fala com a criança. É necessário realizar futuramente análises acústicas para comprovar ou não tal observação.

Os exemplos a seguir são recortes que ilustram a presença das características elencadas acima da linguagem dos professores dirigida às crianças nessa escola. 
(1) Um exemplo de solicitação para se falar em uma determinada língua, o que não foi encontrado com muita frequência nos dados:

Na sessão 1, a professora M. senta em roda com as crianças e sugere:

P: Today we are only going to sing English songs. What do you think?

[A professora canta uma sequência de músicas já conhecidas pelas crianças em inglês. Entre uma música e outra, algumas vezes, as crianças pedem, em português, alguma música conhecida em língua portuguesa, como "na careca do vovô"], ao que a professora respondeu:

P: Today we are only going to sing English songs, we made a deal, do you remember? What song would you like to sing in English?

Ou ainda, em outro momento:

P: Ok, but this song is in Portuguese, today we are only singing songs in English, is that ok for you?

(2) Após cantarem algumas músicas, a professora V. chega na sala com as garrafas de água das crianças, elas bebem e formam um círculo novamente. Um exemplo da reformulação para o inglês acontece depois desse momento de beber água. Foi derramada água no chão e, quando as crianças vão se sentar, uma delas, ainda de pé, aponta para o chão e diz:

F: (es)tá molhado.

$P:$ is it wet?

A criança responde afirmativamente com a cabeça.

P: so sit here please. - e dá dois tapinhas com a mão no chão, indicando outro lugar para a criança sentar. A criança anda até o lugar indicado e se senta.

Esse tipo de reformulação dos enunciados das crianças em português para o inglês é um recurso recorrente das professoras nessa escola bilíngue, o que poderia ser reconhecido como uma característica desse gênero nessa escola. A criança diz algo em português e a professora confirma/reformula o que ela disse em inglês. Isso pode acontecer não só 
na escola, como também em famílias bilíngues e, segundo Aimard (1998), que fala de crianças monolíngues, essa pode ser uma estratégia favorável ao processo de aquisição/ aprendizagem da criança.

Nessa escola, nessa etapa da El como na maioria das escolas bilíngues de imersão no Brasil, a maior parte das aulas é em inglês, a fim de que o contato com a L2, que não é a língua da sociedade em que as crianças vivem, quase se equipare ao contato com a L1. Na escola em questão, uma das aulas em português é a chamada Nosso Brasil, em que são abordados aspectos da cultura brasileira. O tema dessa aula foi o Saci.

(3) Na sessão 1, a professora fala alguma coisa em inglês e introduz a fala em português como transcrito abaixo, colocando uma tiara na cabeça. O uso da tiara é uma escolha da escola: quando as professoras falam em português, usam uma tiara para identificar a língua com a qual se dirigem às crianças.

A professora está com a tiara na mão, a coloca em frente ao rosto, prestes a vesti-la e chama a turma (essa turma é nomeada Bumblebees):

P: Bumblebees, what am I going to do now? ... speak in...

Algumas crianças: português!

[A professora veste a tiara].

P: Muito bem.

$[\ldots]$

P: Que aula que a gente tem em português? Chama nosso ...

Crianças: Brasil!

Esse "recurso" da LDC - dedução/reformulação - contribui para a colocação da criança como sujeito do discurso na interação com o outro, promove a troca entre os interlocutores e ajuda a estabelecer a comunicação entre "o mundo da criança e o mundo do adulto", por assim dizer.

Quanto ao léxico característico da LDC familiar, apareceram algumas palavras infantilizadas na linguagem do professor enquanto dirigia-se à criança; da mesma forma, 
é recorrente o fato de as professoras chamarem as crianças pela primeira sílaba de seus nomes, de forma duplicada.

Na sessão 5, em 01 de novembro de 2016, as professoras M. e V. estão com todas as crianças na sala falando em inglês sobre lugares da cidade: shopping, padaria, etc. Cada uma das crianças tem nas mãos uma maquete de uma casa feita de material reciclável, enquanto a professora tem em mãos maquetes de lugares da cidade.

A professora pergunta para cada uma das crianças qual é o lugar preferido delas na cidade. Então ela pergunta a A.:

(4) M: What about you, A., what is your favorite place?

A. mexe com a maquete que tem nas mãos. A outra professora, $V_{\text {., }}$ está ao lado dela, enquanto M. está do lado oposto.

V: What is your favorite place?

M: Here in Araraquara?

A: [ininteligível]

V: Hã?

A: Minha casa . [fala muito baixo].

V: What? [inclina-se para perto da criança].

A: Minha casa.

V: I don't understand, $A$.

A: Minha casa. [ela fala olhando para a câmera].

M: Your home?

V: Your home? 
M: Yes?

$\mathrm{V}$ : Yes, is it your home?

[A. acena afirmativamente com a cabeça para V., que acena com a cabeça para M.]

Aqui, as professoras realmente não ouviam o que a criança estava falando e buscaram compreender, por meio da dedução/reformulação, o que ela quis dizer, estabelecendo a comunicação. É uma situação típica da LDC em que o adulto, com os discursos que já tem assimilados, entende uma coisa a partir da fala da criança, ou, no caso de crianças menores, a partir de um choro ou um gesto. A criança, utilizando dos recursos linguísticos que tem disponíveis naquele momento para se comunicar, se coloca nessa interação, demonstrando se aceita ou não a proposta do adulto e, por vezes, dando outras propostas. Esclareceremos melhor isso com os próximos exemplos.

Situações como essa, com dedução e reformulação, aconteceram várias vezes tanto em inglês quanto em português. Em algum momento, essa característica pode fazer parte da comunicação, embora não estabelecendo o entendimento real entre os interlocutores. Ao analisar os vídeos com mais atenção, observamos um momento em que a comunicação é estabelecida pela negociação das reformulações dos enunciados da criança propostas pelo adulto, sem que o professor entenda exatamente o que a criança quis dizer. Nesse diálogo, a criança confirma uma dedução do adulto, mesmo sem ele ter dito exatamente a palavra que a criança queria dizer, estabelecendo a comunicação em um outro sentido. Isso acontece no exemplo seguinte da sessão 2:

(5) A professora V. está levando as três crianças para a sala de leitura, onde fizemos a atividade para filmagem.

L: [ininteligível. Aponta para um lugar onde há brinquedos e uma piscina. A professora abaixa-se para tentar escutá-lo].

V: Uma bola. Uma bola?

L: Não.

V: É uma o quê?

L: É uma / uma / uma fita grande . 
V: Barbatana?

L: Não.

[A observadora ri].

V: O quê, então?

L: Uma corda! [e pula no lugar].

V: Hum... uma cobra!

L: Sim.

V: Uma cobra! ...Por que que quando eu te perguntei se era uma cobra você me falou que não era uma cobra?

L: Uma / uma corda de [ininteligível].

V: Uma cobra te pegou?

Pegou você, A.? - volta-se para A.

Pegou você, F.? - volta-se para F.

F: Pegou.

Observa-se que a professora faz várias deduções/reformulações da fala da criança, que, por sua vez, vai negociando com as sugestões do adulto até encontrar uma que ela aceita. No entanto, nesse caso, a palavra dita pelo adulto não era exatamente a que a criança havia dito, mas o encadeamento discursivo aqui fez com que a professora entendesse que sua sugestão havia sido aceita, e isso a faz mudar o rumo da conversa para uma brincadeira sobre uma cobra imaginária. 


\section{Recorrências de uma LDC características da escola}

A partir da análise dos dados buscando características da LDC, pudemos observar que a forma pela qual os professores dessa escola dirigem-se às crianças apresenta características dessa maneira particular de falar.

Apesar dos aspectos comuns à LDC familiar que apareceram nos dados coletados na escola bilíngue, e de terem sido observados aspectos particulares da linguagem do professor para dirigir-se à criança, pudemos perceber que a LDC do professor se compõe diferentemente ainda da linguagem familiar em outros aspectos, que estão ligados ao contexto escolar em que ocorre a interação. O gênero escolar "bilíngue" parece, assim, ter suas peculiaridades, inclusive no que se refere à LDC. A situação - um desses aspectos - diz muito para que a criança compreenda e dê ao professor a resposta esperada. Os educadores constroem um contexto e dão informações não apenas linguísticas para que o aluno entenda o que ele diz. Os exemplos abaixo deixarão isso mais claro.

Também os gestos que acompanham a fala da professora têm a intenção de auxiliar as crianças a compreenderem o que ela quer dizer, de uma maneira didática. Outro exemplo abaixo servirá de ilustração para essa observação. Levamos em conta os trabalhos de McNeill (1985), que defende que gesto e fala são parte da mesma estrutura psicológica. Isso porque, segundo o autor, há relações muito próximas entre fala e referencial e gestos orientados pelo discurso nos campos temporal, semântico e pragmático. Assim, ainda que não haja um trabalho de conscientização do uso desses recursos multimodais, os professores auxiliam a compreensão da língua inglesa, que não é a língua materna das crianças, por meio da associação gesto-fala.

Assim, entendemos que as professoras registradas em sala de aula, no caso desta pesquisa, dirigem-se às crianças de uma maneira singular, o que nos permite dizer que elas utilizam uma LDC particular, com algumas especificidades que não são vistas com muita frequência na LDC da mãe, por exemplo. Citaremos algumas características ligadas a esse contexto escolar particular que observamos nos dados, e que acabavam suscitando nas professoras uma maneira particular de se dirigir às crianças.

Um desses contextos envolve as músicas da escola. Há músicas padrão que são repetidas e conhecidas pelas crianças para alguma atividade determinada, frequentemente cantadas em inglês, que acompanham gestos e ações. Notamos a repetição dessas músicas em momentos como a hora de guardar os brinquedos (clean up), momento de fazer uma roda (let's make a circle) e quando as professoras guiam as crianças em fila para se locomoverem de um lugar para outro da sala. Quando essas situações de música apareceram nos registros, em três situações diferentes e em meses distintos, as crianças raramente cantaram junto com as professoras, mas pareceram entender 0 que esse momento com essa música significa, e começaram a guardar os brinquedos 
ou a sentarem-se em círculo. Diferente dessas músicas, o exemplo (6) traz um momento destinado a cantar músicas que acompanham gestos, mas não representam um pedido de ação para as crianças. Nesse caso, as crianças costumam cantar junto com a professora.

(6) No início da sessão 1, a professora combina com os alunos que eles só cantariam músicas em inglês, e pergunta quais músicas eles gostariam de cantar. As crianças escolhem várias músicas durante a aula, mas nunca as duas acima citadas (clean up ou let's make a circle). O momento de cantar músicas é uma atividade separada, na qual as crianças sentam-se em círculo e cantam juntas, seguindo uma espécie de coreografia de gestos relacionados às letras das músicas, quando é esse o hábito.

Em se tratando de uma escola, há objetivos a serem cumpridos e conteúdos programados, e também um vocabulário planejado para as crianças aprenderem em inglês, o que já difere esse processo elaborado e estruturado daquele da aquisição de língua materna. O exemplo (7) ilustra essa característica da linguagem do contexto escolar.

(7) Em 18 de novembro de 2016, registramos uma atividade em que, após as professoras terem trabalhado com as crianças durante algumas semanas um vocabulário de animais e a distinção entre wild animals (animais selvagens) e farm animals (animais da fazenda), as crianças sentaram-se em linha à frente da professora, entre ela e vários animais de brinquedo, selvagens e da fazenda. Ao chamado da professora, cada criança pegava um brinquedo e separava-o em duas caixas, uma de animais selvagens e outra de animais da fazenda. As crianças observaram a atividade dos colegas e esperaram em silêncio, atentas às classificações e às perguntas da professora: "Is this a wild animal or a farm animal?".

O exemplo (8), por fim, a seguir, ilustra o papel da gestualidade na LDC pelo professor no esforço de fazer-se entender pela criança, e a atribuição de sentido que as crianças deram a esses gestos, unindo contexto e as oralizações que acompanhavam os gestos. Entre adultos de um mesmo extrato sociocultural, gestos emblemáticos têm significados parcialmente convencionados (KENDON, 1982). Esses gestos não são sempre os mesmos em todas as situações e não têm exatamente a mesma forma pela produção de diferentes sujeitos e pelo mesmo sujeito em diferentes momentos. Por exemplo, um gesto para demonstrar fome pode ser expressado de diversas maneiras. Nós entendemos os significados desses gestos porque já tivemos vivências de vários sujeitos produzindoos de maneiras diferentes em um mesmo contexto. As crianças vão adquirindo os significados desses gestos também pelas vivências que vão tendo, nos meios em que convivem. Dessa forma, se em casa, dirigem à criança um determinado gesto para fome, na escola a criança pode entrar em contato com diversos outros gestos, que ela pode adicionar ao sentido de "fome". 
(8) Em 22 de setembro de 2016, após uma atividade de leitura logo antes da hora do almoço, uma das professoras disse:

P: - what do we have now? Our... - e colocou a mão em frente à boca aberta, com a palma virada para cima e mexendo os dedos na direção da palma da mão, pretendendo que as crianças respondessem que era hora do almoço. O gesto grande da professora foi, no entanto, interpretado de outra maneira por L., que respondeu:

L: - boca! - e a professora riu, e respondeu:

P: - Nice, very smart!

Isso ocorre principalmente porque a criança não vê o mundo da mesma forma que o adulto, por assim dizer. É por isso que enxergamos graça em enunciados infantis em que a criança não tinha, necessariamente, o desejo de fazer o outro rir (DEL RÉ; DE SANTIS, 2017).

\section{Considerações finais}

Como pudemos confirmar a partir da análise dos dados, as características da LDC trazidas pela literatura não são, de fato, exclusivas da linguagem da mãe dirigida à criança, e as características aqui salientadas puderam ser verificadas na linguagem das educadoras dirigida às crianças.

A LDC das pessoas de fora da família, no entanto, não é como a da mãe da criança. A afetividade sempre será diferente e, por mais que algumas características dessa "linguagem especial" sejam recorrentes na escola, a LDC dos professores não será como a da mãe. Isso pode implicar um processo de aquisição/aprendizagem do inglês diferente do processo que as crianças passam com o português. Assim, convém-nos a classificação de Marcelino (2009) dessas crianças inseridas nesse novo tipo de escola como um tipo de bilíngue diferente, que não é o consecutivo (a criança primeiro adquire a LM e por volta dos cinco anos adquire a segunda língua) nem o simultâneo (a criança é exposta a duas ou mais línguas desde o nascimento, MEGALE, 2005), mas o que ele chama de bilíngue consecutivo de infância. Mesmo tendo contato com o inglês desde muito pequenas na escola, a partir dos quatro meses, essa língua chega aos ouvidos das crianças, filhas de pais não-falantes de inglês após a chegada do português, e de uma forma distinta do português.

Assim, não podemos considerar apenas o tempo de início de contato das crianças com a outra língua, pois se assim fosse, concordaríamos com De Houwer (1990), que, estudando bilíngues "típicos", em contextos em que os pais falam duas línguas diferentes 
com as crianças, aos quatro meses o bilíngue ainda pode ser considerado um bilíngue simultâneo. No contexto específico das escolas bilíngues, onde a LDC não é a mesma que a familiar, devemos levar em conta também a maneira como as crianças adquirem/ aprendem a $L 2$, que é distinta daquela da L1, pois estão inseridas em contexto escolar.

Por terem contato com o inglês apenas nesse contexto, as propostas de interação em inglês devem proporcionar simulações e propor conteúdos do dia a dia que as crianças reconhecem em português, mas não em inglês. Observamos exemplos disso com as aulas em inglês sobre os animais, sobre os locais da cidade e os cômodos da casa e a rotina do calendário, que é feita todos os dias em inglês e alguns dias em português. Esses conteúdos são passados para as crianças com o objetivo de criar um repertório lexical e situacional, mesmo que em uma interação mais natural do que em uma escola de idiomas. A língua-alvo, mesmo sendo língua de instrução, é também a língua de estudo, e isso também torna o processo de aquisição/aprendizagem dessa língua diferente daquele da língua materna, em que a criança vai adquirindo repertório naturalmente, ao longo da sua vida, nas situações reais que passa junto à comunidade falante da sua língua materna (L1).

É intrigante - e importante para reflexões sobre educação - observar que também a mãe e a família da criança, de maneira geral, têm um papel essencial na educação das crianças, fazendo com que os familiares adotem posturas muito parecidas com as de educadores, por vezes também trabalhando com a construção de repertório lexical de seus filhos, por exemplo. No entanto, essa linguagem ainda demonstra ter receptividade e respostas diferentes do processo de aquisição da (L1).

A maneira como a fala das mães é dirigida às crianças pode estar relacionada a dois aspectos: primeiro o fato de as mães possuírem socialmente o papel de educadoras e, segundo, conhecerem melhor a realidade dos seus filhos. Como educadora, a mãe se sente na responsabilidade de ensinar a criança e, progressivamente, apropria-se da linguagem compatível com o nível linguístico da criança, o que favorece o desenvolvimento da linguagem na medida em que permite dar continuidade à conversação entre os parceiros conversacionais (FONSECA; SALOMÃO, 2005).

É interessante notar que as características da LDC aparecem na linguagem do professor tanto em inglês quanto em português, mesmo que nenhuma das professoras seja falante nativa de inglês, e tenha o português como língua materna. Isso pode ser observado mesmo tendo sido coletados mais dados de interações em inglês do que em português. Para pesquisas futuras, seria interessante procurar equilibrar os dados nas duas línguas, a fim de analisar se há diferenças na LDC em cada língua por cada um dos professores.

A análise dos dados focalizada na linguagem do professor permitiu verificar que cada um deles dirige uma linguagem particular às crianças, cada qual à sua maneira. 
Exemplificando com uma observação geral, a professora Fabiana mantém um tom de voz baixo e calmo, mais do que quando se dirige a um adulto; enquanto a Mônica fala mais alto com as crianças do que com os adultos e promove mais brincadeiras e alguns jogos de linguagem. A professora Bárbara, por sua vez, não parece, em um primeiro momento, modificar muito sua linguagem quando dirigida à criança, por exemplo, em uma observação superficial sobre sua prosódia, como feito para as outras duas professoras, a de Bárbara não parece se alterar. As características da linguagem de cada professor demonstram marcas de singularidade que aparecem e, assim, podem ser analisadas no discurso em trabalhos futuros.

É possível notar que as crianças apreendem a L2 por meio da LDC do professor e por hábitos que são criados na escola, ligados às atividades e aos comandos em inglês. Embora as crianças analisadas nesta pesquisa, entre 2 e 3 anos não produzam muitos enunciados em inglês, notamos, pelas suas respostas, que elas demonstram compreender e lidar bem com a abordagem da língua inglesa na escola, como visto no estudo de Letícia Gonçalves (2017), complementar a este. No entanto, é relevante observar, como afirma Marcelino (2009), que mesmo a outra língua estando presente na escola e, diremos aqui, mesmo com essa LDC particular em outra língua na escola provendo à criança condições favoráveis para aquisição/aprendizagem de outra língua, o uso que a criança fará dessa língua depende de outros fatores que apenas ela determinará.

A coleta de dados na escola continua para pesquisas futuras com dados desta escola bilíngue, e o crescimento das crianças, o desenvolvimento linguístico delas e a criação de novos contextos comunicativos, bem como os conteúdos das aulas deverão influenciar a relação dessas crianças com suas línguas. Na continuidade do estudo em pesquisas futuras, acreditamos que os dados coletados até o momento e no futuro terão um papel importante para as reflexões sobre o fenômeno do bilinguismo dentro desse contexto específico de escola bilíngue.

\section{REFERÊNCIAS}

AIMARD, P. O Surgimento da Linguagem na Criança. Porto Alegre: Artmed, 1998.

BAKER, C. Foundations of Bilingual Education and Bilingualism. Clevedon, England: Multilingual Matters, 2001.

BAKHTIN, M., VOLOCHINOV, V. Marxismo e Filosofia da Linguagem. 14. ed. São Paulo: Hucitec, 1988.

BAKHTIN, M. Estética da criação verbal. 2. ed. São Paulo: Martins Fontes, 1997. 
BIJELJAC-BABIC, R. L'enfant bilíngue: de la petite enfance à l'école. Paris: Odile Jacob, 2017.

CAVALCANTE, M. C. B. O estatuto do manhês na aquisição da linguagem. DLCV, João Pessoa, v. 1, n. 1, p. 147-156, out. 2003.

CAVALCANTE, M. C. B. Contribuições dos estudos gestuais para as pesquisas em aquisição de linguagem. Revista Linguagem \& Ensino, Pelotas, v. 21, n. 1, p. 5-35, 2018. Disponível em: $\quad$ https://periodicos.ufpel.edu.br/ojs2/index.php/rle/article/download/15199/9377. Acesso em: 05 out. 2018.

CAVALCANTI, M. C. Estudos sobre educação bilíngüe e escolarização em contextos de minorias lingüisticas no Brasil. DELTA, São Paulo, v. 15, n. esp., p. 385-417, 1999. Disponivel em: http://www.scielo.br/scielo.php?script=sci_arttext\&pid=S010244501999000300015\&lng=en\&nrm=iso. Acesso em: 12 mar. 2017.

CHOMSKY, N. Aspects of the Theory of Syntax. Cambridge, MA: MIT Press, 1965.

DE HOUWER, A. The acquisition of two languages from birth: A case study. Cambridge: Cambridge University Press, 1990.

DEL RÉ, A.; DE PAULA, L.; MENDONÇA, M. C. (org.). A linguagem da criança: um olhar bakhtiniano. São Paulo: Contexto, 2014a.

DEL RÉ, A.; DE PAULA, L.; MENDONÇA, M. C. (org.). Explorando o discurso da criança. São Paulo: Contexto, 2014b.

DEL RÉ, A.; DE SANTIS, A. Algumas reflexões sobre a constituição do discurso humorístico infantil: o caso de uma criança bilíngue franco-brasileira. In: BARBOSA, M. V.; MORAES, C. F.; VIDAL, M. E. B. Teorias de Linguagem: Pesquisa e Ensino. São Paulo: Mercado das Letras, 2017.

DEL RÉ, A.; HILÁRIO, R. N., MOGNO, A. S. Programa CLAN da base CHILDES: normas de transcrição (CHAT) e comandos básicos. In: FERREIRA-GONÇALVES, G.; BRUM-DEPAULA, M. R.; KESKE-SOARES, M. (org.). Estudos em Aquisição Fonológica. v. 4. Pelotas: Gráfica e Editora Universitária-UFPel, 2012. p. 11-30. 
DEL RÉ, A.; HILÁRIO, R. N.; VIEIRA, A. J. Subjetividade, individualidade e singularidade na criança: um sujeito que se constitui socialmente. Bakhtiniana, São Paulo, v. 7, n. 2, p. 5774, jul./dez. 2012. Disponível em: http://www.scielo.br/pdf/bak/v7n2/05.pdf. Acesso em: 10 out. 2014.

FONSECA, P. N.; SALOMÃO, N. M. R. Análise comparativa das falas maternas e paternas dirigidas às crianças. Paidéia, Ribeirão Preto, v. 15, n. 1, p. 79-91, 2005.

GONÇALVES, L. S. Aquisição/aprendizagem de inglês em uma escola bilíngue do Estado de São Paulo: o caso de três crianças brasileiras em uma sala da educação infantil. 2017. Graduação (Relatório de Iniciação Científica) - Faculdade de Ciências e Letras, Universidade Estadual Paulista "Júlio de Mesquita Filho", Araraquara, 2017.

GROSJEAN, F. Life with Two Languages: An Introduction to Bilingualism. Cambridge, Mass: Harvard University Press, 1982.

HARMERS, J.; BLANC, M. Bilinguality and Bilingualism. Cambridge: Cambridge University Press, 2000.

HERNAIZ, I. Educação na Diversidade. Experiências e Desafios da Educação Intercultural Bilíngue. v. 28. Coleção Educação para todos. Brasília: Ministério da Educação, 2007.

KENDON, A. The study of gesture: Some observations on its history. Recherches Sémiotiques/Semiotic Inquiry, v. 2, n. 1, p. 45-62, 1982.

MACWHINNEY, B. The CHILDES Project: tools for analyzing talk. The database. 3. ed. v. 2. Mahwah, NJ: Lawrence Erlbaum Associates, 2000.

MARCELINO, M. Bilinguismo no Brasil: significados e perspectivas. Revista Intercâmbio, São Paulo: LAEL/PUC-SP, v. XIX, p. 1-22, 2009.

MATTOS, T. Escolas bilíngues atraem novo perfil de aluno. Estadão. Caderno de Educação, 2013. Disponível em: http://educacao.estadao.com.br/noticias/geral,escolas-bilinguesatraem-novo-perfil-de-aluno,1075469. Acesso em: 30 ago. 2015.

MCNEILL, D. So you think gestures are nonverbal? Psychological Review, v. 92, n. 3, p. 350$371,1985$. 
MEGALE, A. H. Bilinguismo e educação bilíngue - discutindo conceitos. Revista virtual de Estudos da Linguagem - ReVEL, ano 3, n. 5, p. 1-13, 2005. Disponível em: http://www. revel.inf.br/files/artigos/revel_5_bilinguismo_e_educacao_bilingue.pdf. Acesso em: 12 fev. 2017.

MEGALE, A. H. Duas línguas, duas culturas? A construção da identidade cultural de indivíduos bilíngues. Revista Veredas - Atemática, Juiz de Fora, v. 1, p. 90-102, 2009. Disponível em: http://www.ufjf.br/revistaveredas/files/2009/12/artigo062.pdf. Acesso em: 28 out. 2013.

PERRI, M. A alfabetização em escolas bilíngues: possibilidades e consequências. Pedagogia ao Pé da Letra. Educação. 2013 [não paginado]. Disponível em: http:// pedagogiaaopedaletra.com/a-alfabetizacao-em-escolas-b.... Acesso em: 30 ago. 2015.

PIMENTEL, C. J.; TAMI, J. A chegada dos imigrantes. Revista Educação (on-line), 2015. Disponível em: http://revistaeducacao.uol.com.br/formacao-docente/174/a-ch. Acesso em: 03 jun. 2015.

SNOW, C.; FERGUSON, C. (org.). Talking to children: Language, input and acquisition. Cambridge: Cambridge University Press, 1977. 